http://jmscr.igmpublication.org/home/

ISSN (e)-2347-176x ISSN (p) 2455-0450

crossref DOI: https://dx.doi.org/10.18535/jmscr/v8i2.165

Journal Of Medical Science And Clinical Research

\title{
Complete En Bloc Resection of Giant Ovarian Tumour
}

\author{
Authors \\ Dr Dhanabir Thangjam", Dr MC Mascot Ningshen ${ }^{2}$, Dr Pani Veihrii Paul, \\ Dr Vishakha Silky ${ }^{4}$, Dr N.Somorjit Singh ${ }^{5}$ \\ ${ }^{1}$ Senior Resident, Department of Surgery \\ ${ }^{2,3,4}$ Post Graduate Student, Department of Surgery \\ ${ }^{5}$ Professor, Department of Surgery \\ Jawaharlal Nehru Institute of Medical Sciences, Porompat, Imphal East, Manipur, India
}

\begin{abstract}
Giant ovarian tumours are rare. It is defined as tumor measuring more than $10 \mathrm{~cm}$. Benign mucinous cyst adenomas account for about 15\% of all ovarian neoplasms and are among the largest known tumours. About $80 \%$ of mucinous tumours are benign, $10 \%$ are borderline and $10 \%$ are malignant. They are usually common between third and fifth decade of life. We present a case report a 78 years old lady present with large abdominal pelvic mass which was successfully resected completely and specimen measured $30 \times 30 \times 15 \mathrm{~cm}$. It was report as mucinous cystadenoma of ovary in final histo-pathological examination.

Keywords: Giant ovarian tumour, Mucinous cystadenoma ovary, Complete en bloc.
\end{abstract}

\section{Background}

Giant ovarian tumours are defined as tumour size measuring more than $10 \mathrm{~cm}$ in diameter in preoperative scans or those reaching above the umbilicus ${ }^{1}$.In the present era of medical practice, giant ovarian tumors have become rare due to early discovery on routine check-ups. Ovarian mucinous cystadenoma is a benign tumour that arises from the surface epithelium of ovary. It constitute about $15 \%$ of all ovarian tumours. About $80 \%$ of mucinous tumours are benign, $10 \%$ are borderline and $10 \%$ are malignant.In addition to this, large size of these tumors causes mechanical pressure symptoms on the gastrointestinal, respiratory and urinary tract. Role of imaging modalities such as CECT and MRI scan gives better idea about the nature and extension of the tumor. Surgical expertise is required for complete resection and prevent complications in such huge tumors where the anatomical planes are usually distorted. ${ }^{2.3}$

\section{Case Presentation}

A 78 years old multiparous lady presented with gradually increasing abdominal girth since five years .She also notice a vague swelling in her lower abdomen since three years. She experience lower abdominal pain, early satiety, reduce appetite and increase frequency of urination. She has weight loss of $4 \mathrm{~kg}$ within last three months. She had two pregnancies and produced two children which were born with normal vaginal deliveries. She has no history of usage of any contraceptives. Her menopause occurred at age of 
48 years. She has history of radiotherapy for cervical cancer around15 years ago but no proper follow up since 10 years. No other significant past medical and surgical history. Despite all these symptoms, the patient did not seek for medical attention earlier owing to low socioeconomic status. She was only brought to hospital when she started having decreased appetite.

Physical examination revealed a temperature of $97^{\circ} \mathrm{F}$, respiratory rate of 25 breaths/minute, a pulse rate of 98 beats per minute, blood pressure at $110 / 60 \mathrm{mmHg}$; Her performance status is ECOG 2 and body mass index of 18.3.Per abdomen examination reveals a large abdomino-pelvis mass corresponding to 38 weeks size gravid uterus which is extending to both flanks. (Fig.1a \& 1b) There are visible dilated and tortuous veins over skin abdomen. The mass is non-tender, firm to cystic in consistency with restricted mobility. Signs of free fluids were positive. Normal bowel sound heard. On per vaginal examination cervical os and fornix were normal .Per rectal examination was normal. Cardiac and respiratory sound were normal. Examination of her breasts did not reveal abnormalities. Laboratory tests revealed haemoglobin of $9.0 \mathrm{~g} / \mathrm{dL}$, leukocytes of 6300 cells $/ \mu \mathrm{L}$, platelets of $400,000 / \mu \mathrm{L}$, S.total bilirubin of 0.6 , alkaline phosphate of 68 , and S. Albumin of 3.1. Her Renal function test were within normal limits. Chest X ray showed normal lung fields and ribs. S. CA 125 levels was $10.53 \mathrm{u} / \mathrm{ml}(<35)$, S.CEA measured $2.53 \mathrm{ng} / \mathrm{ml}$ (0-5).USG abdomen showed a large abdominopelvic cystic lesion with multiple septations and an impression of mucinous cyst was given. CECT abdomen and pelvis was done which showed a large multiloculated cystic mass measuring 28 x 26x $15 \mathrm{~cm}$ arising from right adnexa with enhancing internal septations and displacing the bowel loops peripherally. There were no enlarged retroperitoneal lymph nodes and uterus was atrophic. Feature suggestive of mucinous ovarian cystadenoma or ovarian adenocarcinoma. (Fig.2a $\& 2 b)$
An exploratory laparotomy was done. A large multilocualted tumor arising from the right ovary was seen occupying the abdomen, from the pelvis up to the upper quadrant of abdomen and tumor was seen displacing bowel loops. The extent of the tumor was identified. Gross evidence of malignancy was ruled out. The tumour was completely resected en bloc with total abdominal hysterectomy, bilateral salpingo-oophorectomy with omentectomy .As the tumour was adherent to adjacent peritoneal surface, bilateral parietal\& pelvic peritonectomy was also performed. The resected specimen measured $30 \mathrm{~cm}$ x $30 \mathrm{~cm} \times 15$ $\mathrm{cm}$ and weighed $7.5 \mathrm{~kg}$. (Fig.3a \& 3b) She was kept in surgical intensive care unit after surgery and she was give 2 units of packed red blood cells as her immediate haemoglobin was $6.9 \mathrm{gm} / \mathrm{dl}$. On the $3^{\text {rd }}$ post-operative day she was shifted to ward and discharged on $7^{\text {th }}$ post-operative day.

Histopathological examination revealed mucinous cystadenoma of right ovary. Cervix specimen showed features of chronic nonspecific cervicitis but myometrium show presence of tumor emboli of squamous cell carcinoma. To rule out primary site or residual squamous cell carcinoma.

On the follow up, she was referred to Radiation oncologist, in view of possible squamous cell carcinoma of endocervical areas. She was advised for regular surveillance. She is doing well with satisfactory food intake and general well-being. (Fig 4)






\section{JMSCR VoI||08||Issue||02||Page 962-966||February}



Fig. 1a \& 1b: large abdomino-pelvis mass with tortuous dilated veins

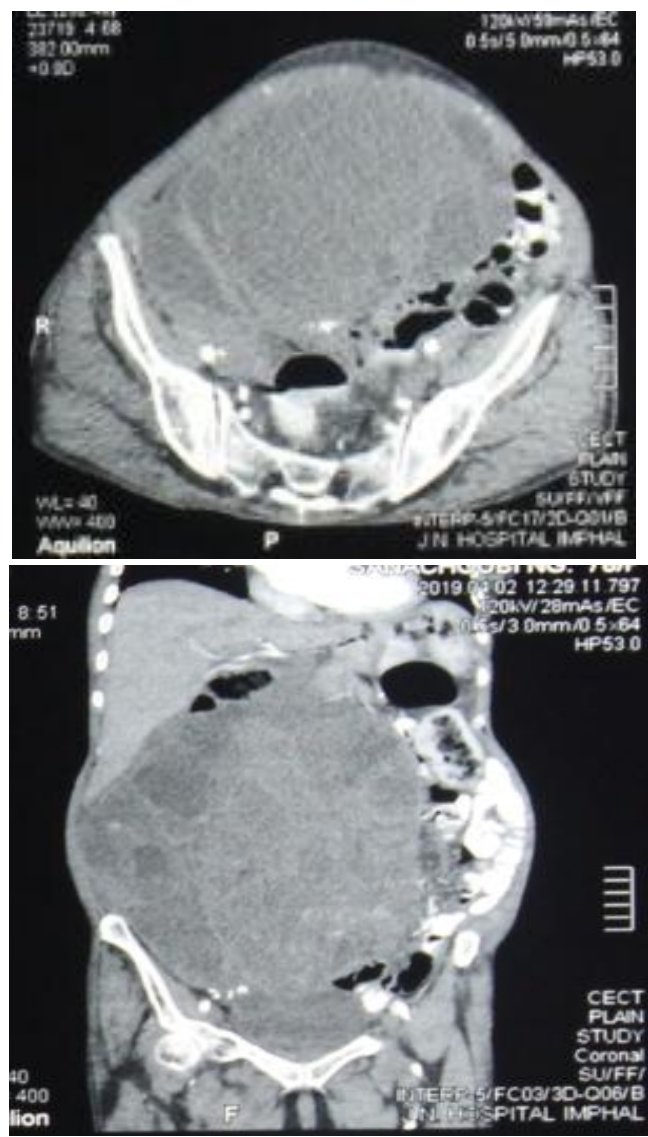

Fig. 2a \& 2b: Right adnexal multi-loculated cystic mass $(28 \times 26 \times 15 \mathrm{~cm})$ with enhancing internal septations and displacing the bowel loops peripherally.
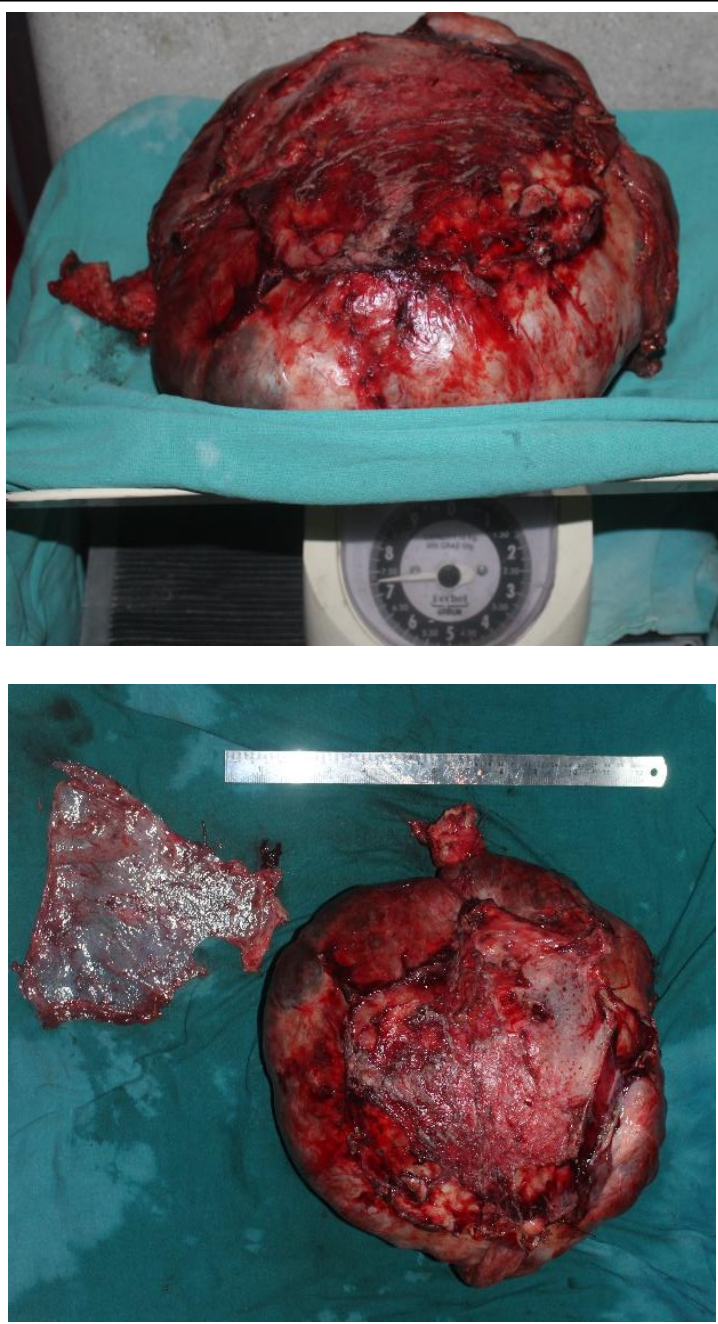

Fig. 3a \& 3b: Complete en bloc resected specimen measured $30 \mathrm{~cm}$ x $30 \mathrm{~cm} \times 15 \mathrm{~cm}$ and weighed $7.5 \mathrm{~kg}$



Figure.4: Post surgery 3 weeks follow up. 


\section{Discussion}

The definition of giant ovarian tumour is that tumour size measuring more than $10 \mathrm{~cm}$ in diameter in preoperative scans or those reaching above the umbilicus ${ }^{1}$. Giant ovarian tumour are usually benign cystic mass and histopathologically these cysts are either serous or mucinous. Serous tumors secrete serous fluids and are originated by invagination of the surface epithelium of ovary. Serous tumors are commonly benign (70\%); 5$10 \%$ have borderline malignant potential, and 20$25 \%$ are malignant. Only $10 \%$ cases of all serous tumors are bilateral. In the literature, a few cases of giant ovarian cysts have been mentioned sporadically and especially in elderly postmenopausal women .Tumors arise from within the pelvis, and patients commonly seek medical aid at advanced stages. ${ }^{3,4}$

Our case is also a postmenopausal elderly lady who has seek medical attention after long standing large mass which is causing pressure symptoms.

It is a challenging condition to diagnose a large abdominal-pelvic masses as the clinical features and findings from physical examination are usually non- specific. Hence modern imaging modalities like computed tomography, magnetic resonance imaging scans are used to diagnose ovarian tumors and to rule out possibility of malignancy. Measurement of biomarkers like CA - 125, Beta HCG, Alfa feto protein are usually helpful. $^{5}$

Giant ovarian tumour require resection because of compressive symptoms or risk of malignancy and their management is complete resection either by laparotomy or laparoscopy without any perforation and spillage of the cyst fluid into the cavity. Leakage of cyst fluid into the peritoneal cavity can cause sudden pulmonary oedema and possibility of pseudomyxoma peritonei ${ }^{6}$. We performed in complete en bloc removal of the mass to prevent spillage and to avoid haemorrhage into the cystic compartments of the mass itself or the abdominal cavity.

As per literature Spohn et al. in 1906 reported a 43 year old woman with a simple abdominal cyst which was drained pre operatively over 7 days of 30 gal of gelatinous fluid. The total weight was $148.6 \mathrm{~kg}$. In 1954 Eames et al. removed an intact tumour weighing $83.46 \mathrm{~kg}$. Symmonds et al. reported another mass that weighed $79.4 \mathrm{~kg}$ in 1963. Jones et al. removed by laparotomy a giant $(21 \mathrm{~kg})$ mucinous cystadenoma of the right ovary detected in a 52-year-old patient in 1992. In 1993 intact removal of a $137.43 \mathrm{~kg}$ ovarian tumour was reported by O'Hanlan. A giant $(30 \mathrm{~kg})$ mucinous cystadenoma was removed by Zanini et al (1996) in a 55-year-old patient. ${ }^{2,7,8}$

Though the reports of giant ovarian masses has declined due to easier access to health care system globally. Nonetheless, rare cases such can still occur due various reasons. In India, largest of its kind was reported by Madhu et al (2013) complete in toto removal of an ovarian cystadenoma weighing $56.95 \mathrm{~kg}$. In 2015, Agrawal et al also report a huge multicystic right ovarian tumor weighing $7 \mathrm{~kg}$ which was complete removed after intraoperative controlled decompression. ${ }^{2,9}$

Complete surgical is essential for all large ovarian tumors even if benign. So far there is no randomized controlled trial for the laparoscopic management of ovarian cysts more than $20 \mathrm{~cm}$ size, so laparotomy remained the ideal method for the excision of the giant ovarian cysts. ${ }^{3,10}$

As reported by previous studies various intraoperative complications during surgical removal of large ovarian tumors, like sudden hypotension due to splanchnic dilatation and venous pooling, decreased venous return and pulmonary edema due to sudden reexpansion of a chronically collapsed lung, which occurred due to compression by the enlarged abdomen. ${ }^{3}$ Therefore, during the management of these high-risk cases of multidisciplinary approach, careful intraoperative and postoperative monitoring are necessary to avoid unwanted complications.

\section{Conclusion}

Mucinous cystadenoma of ovary with complete en bloc surgical resection without spillage is the primarygoal of treatment and has good prognosis. 
The main aim of our case is to highlight one of the giant ovarian tumor which was removed without any dissemination and unwanted perioperative complications.

Conflicts of Interest: No conflicts of interest.

\section{References}

1. Singla DK, Kansal R, Bansal I, Thami G, Agrawal N. Case report: Laparoscopic management of a giant ovarian cyst. Asian Pac J Health Sic 2014; 1:43-6.

2. Y. Madhu, K. Harish, and P. Gotam, "Complete resection of a giant ovarian tumour," Gynecologic Oncology Reports, vol. 6, pp. 4-6, 2013.

3. N. Fatema and M.M AlBadi.A Postmenopausal Woman with Giant Ovarian Serous Cyst Adenoma: A Case Report with Brief Literature Review. Case Reports in Obstetrics and Gynecology Volume 2018, pg 4. https://doi.org/10.1155/2018/5478328.

4. M. Dey and N. Pathak, "Giant serous papillary cystadenoma," Medical Journal Armed Forces India, vol. 67, no. 3, pp. 272-273, 2011.

5. de Lima et al.: A 57-year-old Brazilian woman with a giant mucinous cystadenocarcinoma of the ovary: a case report. Journal of Medical Case Reports 2014 8:82

6. Drife, J.O., Trotter, G.A., 1981. Britain's biggest ovarian cyst? Br. Med. J. 283, 1661.

7. Spohn, A.E., 1905.Multicystic ovarian tumour weighing 328 pounds. Texas. Med. J.1273- 1274.

8. Eames, D.H., 1954. Removal of 184 pound ovarian tumour and observations regarding splanchnic shock. Am. J. Obstet. Gynecol. 67, 1358-1364.

9. Agrawal SP, Rath S K, Aher GS, Gavali UG. Large Ovarian Tumor: A Case Report. Int J Sci Stud 2015; 3(3):143-145.
10. A. Alobaid, A. Memon, S. Alobaid, and L. Aldakhil, "Laparoscopic Management of Huge Ovarian Cysts," Obstetrics and Gynecology International, vol. 2013, pp. $1-4,2013$. 